\title{
Platelet-Derived Growth Factor C
}

National Cancer Institute

\section{Source}

National Cancer Institute. Platelet-Derived Growth Factor C. NCI Thesaurus. Code C104751.

Platelet-derived growth factor C (345 aa, $39 \mathrm{kDa}$ ) is encoded by the human PDGFC gene. This protein plays a role in both growth factor receptor binding and embryonic development. 